\title{
Combined exposure to parasite and pesticide causes increased mortality in the water flea Daphnia
}

\author{
Journal Article \\ Author(s): \\ Buser, Claudia C.; Jansen, Mieke; Pauwels, Kevin; Meester, Luc de; Spaak, Piet \\ Publication date: \\ 2012-06 \\ Permanent link: \\ https://doi.org/10.3929/ethz-b-000049844 \\ Rights / license: \\ In Copyright - Non-Commercial Use Permitted \\ Originally published in: \\ Aquatic ecology 46(2), https://doi.org/10.1007/s10452-012-9397-9
}




\title{
Combined exposure to parasite and pesticide causes increased mortality in the water flea Daphnia
}

\author{
Claudia C. Buser • Mieke Jansen • \\ Kevin Pauwels $\cdot$ Luc De Meester $\cdot$ Piet Spaak
}

Received: 20 January 2012/ Accepted: 25 April 2012/Published online: 15 May 2012

(C) Springer Science+Business Media B.V. 2012

\begin{abstract}
Organisms are exposed to multiple biotic and abiotic environmental stressors, which can influence the dynamics of individual populations and communities. Populations may also genetically adapt to both natural (e.g. disease) and anthropogenic (e.g. chemical pollution) stress. In the present study, we studied fitness consequences of exposure to both a parasite (i.e. biotic) and a pesticide (i.e. abiotic) for the water flea Daphnia. In addition, we investigated whether these fitness consequences change through time as a population evolves. Thus, we exposed Daphnia magna clones, hatched from dormant eggs
\end{abstract}

Handling Editor: Thomas Mehner.

C. C. Buser $(\bowtie) \cdot$ P. Spaak

Aquatic Ecology, Eawag, Überlandstrasse 133, 8600

Dübendorf, Switzerland

e-mail: claudia.buser@eawag.ch

C. C. Buser · P. Spaak

Institute of Integrative Biology, ETH Zürich,

Universitätsstrasse 16, 8092 Zürich, Switzerland

Present Address:

C. C. Buser

School of Biological Sciences, University of Auckland, Private Bag 92019, Auckland 1142, New Zealand e-mail: c.buser@auckland.ac.nz

M. Jansen · K. Pauwels - L. De Meester Laboratory of Aquatic Ecology and Evolutionary Biology, Katholieke Universiteit Leuven, Ch. Deberiotstraat 32, 3000 Leuven, Belgium isolated from different time layers of a natural dormant egg bank, to the parasite Pasteuria ramosa and the insecticide diazinon in a multifactorial experiment. While our experimental treatments for unknown reasons failed to induce disease symptoms in the Daphnia, we did observe a reduced survival of D. magna when simultaneously exposed to both the parasite and the pesticide. No increased mortality upon exposure to individual stressors was observed. We did not observe an evolutionary change in fitness response of the Daphnia clones hatched from different time horizons upon exposure to stressors.

Keywords Daphnia magna Diazinon ·

Dormant eggs · Multiple stressors · Pasteuria ramosa . Parasites $\cdot$ Resurrection ecology

\section{Introduction}

In recent years, the importance of multiple stressors on the health of organisms has received increased attention (e.g. Marcogliese and Pietrock 2011). It is well known that responding to additional disturbances leads to higher costs, which can result in a reduction of fitness of exposed individuals (reviewed in Relyea 2003; Sih et al. 2004). Anthropogenic stress is expected to often increase the incidence and impact of disease in natural populations (e.g. Daszak et al. 2000). Pesticides, for example, are used worldwide in agriculture and have been shown to increase 
susceptibility to parasite infections, as shown for example for oysters (Chu and Hale 1994), amphibians (Gendron et al. 2003; Rohr et al. 2008; King et al. 2010), fish (Kreutz et al. 2010) and planktonic crustaceans (Coors et al. 2008). This synergistic effect may reflect immune suppression by the pesticide (Galloway and Handy 2003) or a cumulative effect of increased energy demand imposed by each of the stressors (Sheldon and Verhulst 1996).

In experimental studies on host-parasite interactions of animals and plants exposed to biotic and abiotic stressors, fitness consequences have often been measured for individuals originating from different locations (King et al. 2010; Schoebel et al. 2010; Bryner and Rigling 2011; Jansen et al. 2011). This approach provides valuable information about patterns of genetic adaptation to local environmental conditions (Kawecki and Ebert 2004). In order to study evolutionary responses to environmental changes, however, it would be necessary to directly track changes over time (De Meester et al. 2007). For such questions, "resurrection ecology" (bringing back ancestors genetic material for transgenerational tests; Kerfoot et al. 1999) can be a powerful tool (Hairston et al. 1999, 2001; Cousyn et al. 2001; Jeppesen et al. 2001; Kerfoot and Weider 2004). This approach is nicely applicable to aquatic organisms, as some species, for example the planktonic crustacean Daphnia, can produce dormant egg stages that can be preserved in the sediment (Carvalho and Wolf 1989; Cáceres 1998). From dated sediments, Daphnia genotypes that were produced at different points of time can be hatched and used in experiments. Several resurrection ecological studies have provided evidence for microevolutionary responses over only a few decades (e.g. Hairston et al. 1999, 2001; Cousyn et al. 2001). For example, Hairston et al. (1999), using Daphnia hatched from a period when toxic cyanobacteria were present in Lake Constance showed that they were more resistant to a diet with cyanobacteria, in comparison with Daphnia hatched from a period when no toxic cyanobacteria were present. Cousyn et al. (2001) documented microevolutionary changes in phototactic behaviour in Daphnia populations in response to changes in fish predation pressure, and Pauwels et al. (2010) showed that the same population also evolved with respect to phenoloxidase activity, a component of the invertebrate innate immunity. Finally, Decaestecker et al. (2007), using both
Daphnia and its microparasite Pasteuria ramosa hatched from different sediment layers, showed strong parasite-host co-adaptive responses.

In the present study, we tested whether the combined exposure to the parasite Pasteuria ramosa (Metchnikoff 1888) and the pesticide diazinon affected the fitness of Daphnia magna (Straus, 1820), hatched from different sediment layers. Whereas the use of diazinon over time is not recorded for the pond where the Daphnia were hatched from, earlier studies on the same population found density differences of $P$. ramosa spores between sediment layers (Decaestecker et al. 2004, 2007). The parasite abundance can influence the host's investment in immunological defences (Schmid-Hempel and Ebert 2003; Lindström et al. 2004); therefore, we expect that hosts hatched from layers with high parasite abundance get less infected than those with lower parasite abundance. It also has been shown that immune defences are coupled with costs (Sheldon and Verhulst 1996; Norris and Evans 2000) and that combined stress can increase infection rates (e.g. Coors et al. 2008). For example, a reinforcement of parasite infection rate in the presence of the organophosphate carbaryl has been shown (Coors and De Meester 2008, 2011; Coors et al. 2008). We expect that the effects of an organophosphate pesticide on Daphnia hatched from sediment layers with high parasite densities may be stronger compared to its effects on Daphnia hatched from parasite-poor sediment layers.

\section{Materials and methods}

Parasite and pesticide used as stressors

As parasite stress, we used the horizontally transmitted Pasteuria ramosa (Metchnikoff 1888; Ebert et al. 1996; Ebert 2005), a gram-positive bacterium cooccurring with Daphnia magna in the field (Ebert 2005). Infected hosts become infertile, the body becomes darkish and grows large and are therefore easily recognizable by eye (Ebert 2005). P. ramosa spores, which are released after host death, are found in pond sediments and remain infective for decades (Decaestecker et al. 2004). As pesticide stress, we used the organophosphate diazinon (O,O-diethyl O-[2isopropyl-6-methyl-4-pyrimidinyl] phosphothionate). This pesticide was developed in 1952 and heavily used 
between 1970 and the early 1980s in many parts of the world. Nowadays, diazinon is still frequently used in agriculture and households and can thus be detected in aquatic environments (Konstantinou et al. 2006; Singer et al. 2010; Wittmer et al. 2010). Acute toxic effects of diazinon (e.g. immobilization and death) are related to the inhibition of acetylcholinesterase, an enzyme essential for proper function of the nervous system (Chambers 1992; Maxwell et al. 2006). Exposure of D. magna to sublethal concentrations of diazinon leads to a delay in reproduction, a decrease in the number and size of offspring, and higher adult mortality (Sanchez et al. 1998).

Origin and culture conditions of the host-parasite system

D. magna host clones were used from a previous study (Decaestecker et al. 2007). The hatched Daphnia came from seven different sediment layers of the Belgian pond OM2 situated in Heverlee $\left(50^{\circ} 51^{\prime} 48^{\prime \prime} \mathrm{N}\right.$, $4^{\circ} 43^{\prime} 16^{\prime \prime} \mathrm{E}$ ), covering a time period of about $17-$ 28 years (Decaestecker et al. 2007). This pond is characterized by epidemics of $P$. ramosa (Decaestecker et al. 2007), as well as intense agricultural activity in the catchments area (Coors et al. 2009). In total, we used 13 genetically different clones, two from each sediment layer, except from the oldest, where only one clone could be used.

$P$. ramosa spores used for infection were obtained by exposing different individuals of a single $D$. magna clone (M10, see Cousyn et al. 2001) originating from the pond Oud Heverlee (Belgium, $50^{\circ} 50^{\prime} 22^{\prime \prime} \mathrm{N}$, $4^{\circ} 39^{\prime} 18^{\prime \prime} \mathrm{E}$ ) to the first few centimetres of the sediment core from pond Knokke Nat (Belgium, $51^{\circ} 21^{\prime} 25^{\prime \prime} \mathrm{N}$, $3^{\circ} 19^{\prime} 50^{\prime \prime} \mathrm{E}$ ), as described in Jansen et al. (2010). The parasites were collected from a different pond than the host clones used in the experiment to avoid possible effects of co-adaption of hosts and parasites (Decaestecker et al. 2007). To increase the amount of $P$. ramosa spores, infected M10 clones were grown for 21 days and used to infect Daphnia juveniles of the same clone for another generation, before using them in the experiment as described in Coors et al. (2008).

\section{Experimental set-up and procedures}

Thirteen clones (from seven sediment layers) were exposed to $P$. ramosa and diazinon (CAS 333-41-5,
99.5\% purity, Ultra Scientific Analytical Solutions, N. Kingstown RI, USA) in a full factorial design and replicated six times, resulting in 312 experimental units. To minimize maternal effects at the start of the experiment, the clones were kept under standard experimental laboratory conditions [1:5 diluted Aachener Daphnien Medium (ADaM, Klüttgen et al. 1994), $20 \pm 2{ }^{\circ} \mathrm{C}, 16 \mathrm{~h}: 8 \mathrm{~h} \mathrm{light/dark}$ photoperiod, fed daily with $2 \times 10^{5}$ Scenedesmus obliquus cells $/ \mathrm{mL}$ ] for at least two generations. To start the experiment, ten third-clutch juveniles (less than $24 \mathrm{~h}$ old) were put together in $250-\mathrm{mL}$ glasses containing $20 \mathrm{~mL}$ of medium. The pesticide treatment consisted of a concentration of diazinon $(0.25 \mu \mathrm{g} / \mathrm{L})$, which is sublethal for Daphnia (Sanchez et al. 1998), whereas the pesticide-free control treatment included the addition of the same amount of the solvent (acetone $0.008 \%$ ). Concentrations of diazinon were verified with spot test with LC-MS/MS as described in Kretschmann et al. (2011) and were all within $\pm 20 \%$ of the nominal concentrations. Individuals belonging to the parasite treatment were exposed on day 0 and day 2 to $3.75 \times 10^{4}$ mature spores of $P$. ramosa per $\mathrm{mL}$ (Jansen et al. 2011). This spore solution was prepared 1 week prior to the experiment and frozen at $-21^{\circ} \mathrm{C}$, a method successfully used in other experiments ( $\mathrm{M}$. Jansen, unpublished). All jars belonging to the control treatment were treated with ground-up, non-infected Daphnia of the M10 clone. On day 5, all Daphnia were transferred into new jars $(500 \mathrm{~mL})$ containing $400 \mathrm{~mL}$ medium, which was renewed every third day thereafter. Animals were checked for infections, the number of offspring was counted and the survival rate was checked daily (and the dead individuals removed) till the end of the experiment (day 21). All traits were quantified as a mean or proportion per set of 10 .

Statistical analyses

Statistical analyses were performed using SPSS 19.0. In total, seven experimental units were lost due to handling errors and excluded from the analysis. Differences in survival rate and reproductive output were analysed using linear mixed effects models, with exposure to parasite (yes/no), exposure to diazinon (yes/no) and sediment layer as fixed factors and clone nested in sediment layer as a random factor. We did not include the interactions between the fixed factors and the random factor clone, as our aims were not 
related to clonal variation. The individual reproductive output was calculated (total amount of offspring born on day $\mathrm{x}$ divided by the total amount of living females on day $\mathrm{x}$, for $\mathrm{x}$ going from day 4 to 21; Van Doorslaer et al. 2009). All residuals were distributed normally.

\section{Results}

In this experiment, no visible signs of infections could be observed at day 21. Nevertheless, significant differences in survival rate were observed when Daphnia were exposed to both stressors: The proportion of surviving individuals was significantly reduced when Daphnia were exposed to parasite spores and the pesticide simultaneously, but not when they were exposed to a single stressor (Table 1; Fig. 1). For individual reproductive output, there was no significant effect of these factors nor of their interactions (Table 1). Further, there were no interaction effects with the sediment layer, nor a main effect of the sediment layer on any of our response variables (all $p>0.1$, see Table 1; Figs. 2, 3). All measured traits were highly variable among clones (Figs. 2, 3).

\section{Discussion}

Our key result is the increased mortality of D. magna upon exposure to both a parasite and a pesticide, even though no parasite infections could be detected

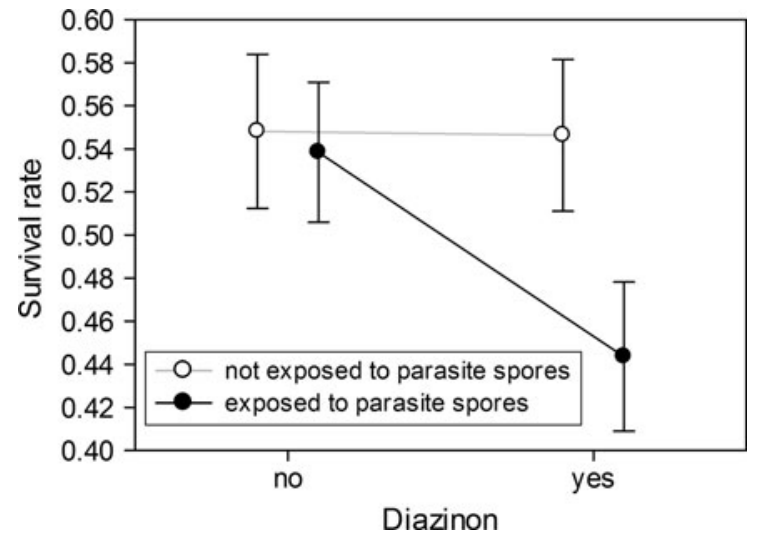

Fig. 1 Mean proportion of surviving individuals per jar $( \pm \mathrm{SE})$ as a function of exposure to the pesticide diazinon (no/yes) and parasite spores $($ no $=$ open circles $/$ yes $=$ closed circles $)$

visually (see further). Many studies showed that the negative effect of two stressors on survival is much stronger compared to individual effects. For example, hosts in poor condition have higher parasite-induced mortality than hosts in good condition (e.g. Braune and Rolff 2001; Krist et al. 2004; Jokela et al. 2005). Immune suppression under direct exposure to pollutants is a well-known phenomenon (e.g. McDowell et al. 1999; Aggarwal et al. 2008), and also diazinon is known to have immunomodulatory effects (Galloway and Handy 2003; Oostingh et al. 2009; Holmstrup et al. 2010). Our results indicate that the defence against parasite spores, even if they do not cause a visible infection, is associated with costs for
Table 1 Results of linear mixed effects models describing the influence of exposure to parasite spores, exposure to diazinon, sediment layer and interactions among these factors on survival and reproduction

\begin{tabular}{lllrrr}
\hline Dependent variable & Source & Numerator $d f$ & Denominator $d f$ & $F$ value & $p$ value \\
\hline Survival rate & Parasite (P) & 1 & 271.03 & 3.01 & 0.084 \\
& Diazinon (DZ) & 1 & 271.03 & 2.88 & 0.091 \\
& Sediment layer (S) & 6 & 6.04 & 1.93 & 0.220 \\
& $\mathrm{P} \times \mathrm{DZ}$ & 1 & 271.09 & 5.10 & 0.025 \\
& $\mathrm{P} \times \mathrm{S}$ & 6 & 271.04 & 0.69 & 0.659 \\
& $\mathrm{DZ} \times \mathrm{S}$ & 6 & 271.03 & 1.60 & 0.147 \\
Reproductive output & $\mathrm{P} \times \mathrm{DZ} \times \mathrm{S}$ & 6 & 271.09 & 0.98 & 0.438 \\
& $\mathrm{Parasite}(\mathrm{P})$ & 1 & 267.06 & 0.87 & 0.351 \\
& Diazinon $(\mathrm{DZ})$ & 1 & 267.14 & 0.28 & 0.597 \\
& $\mathrm{Sediment}$ layer $(\mathrm{S})$ & 6 & 6.03 & 2.19 & 0.180 \\
& $\mathrm{P} \times \mathrm{DZ}$ & 1 & 267.15 & 0.23 & 0.629 \\
& $\mathrm{P} \times \mathrm{S}$ & 6 & 267.07 & 1.04 & 0.398 \\
& $\mathrm{DZ} \times \mathrm{S}$ & 6 & 267.15 & 1.64 & 0.136 \\
& $\mathrm{P} \times \mathrm{DZ} \times \mathrm{S}$ & 6 & 267.16 & 1.32 & 0.248 \\
\hline
\end{tabular}


Fig. 2 Mean proportion of surviving individuals per jar $( \pm \mathrm{SE}$ ) for each clone per sediment layer (from deepest (7) to newest (1) sediment layer) as a function of exposure to the pesticide diazinon (no $=$ circles $/$ yes $=$ squares) and parasite spores $($ no $=$ whitel yes $=$ black)
Fig. 3 Mean amount of offspring per female per day (reproductive output; \pm SE) for each clone per sediment layer (from deepest (7) to newest (1) sediment layer) as a function of exposure to the pesticide diazinon (no $=$ circles $/$ yes $=$ squares) and parasite spores $($ no $=$ whitel yes $=$ black)
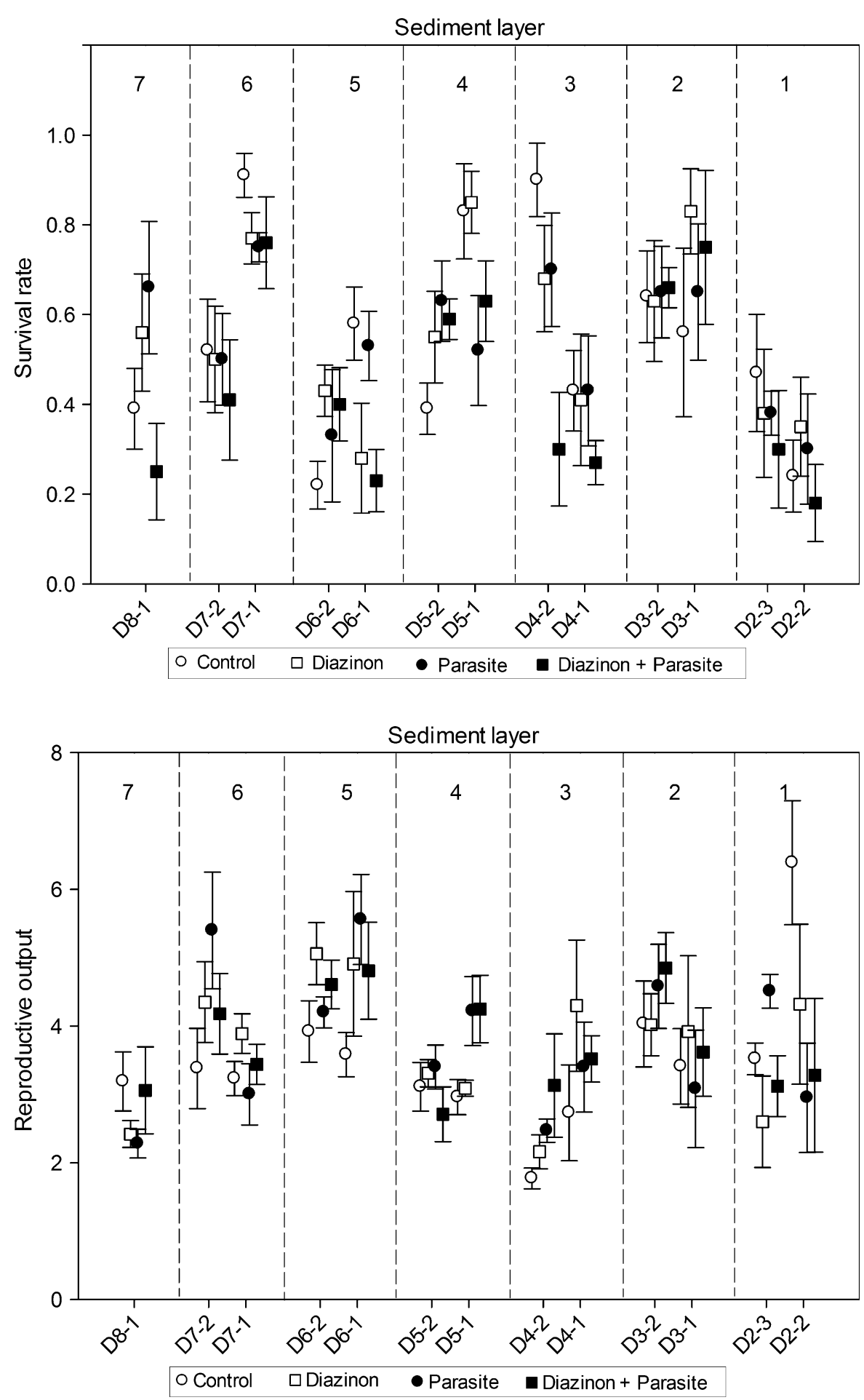

D. magna. Another study also found costs of defences in Daphnia. Yin et al. (2011) showed that defence against predators induced stronger disease progression in Daphnia. Here we show that the enhanced costs of defending against parasite spores, even if they do not cause visible infections, increase mortality upon 
exposure to a pesticide. Our findings agree with the study of Coors et al. (2008), who showed that exposure to pesticides increased disease progression in Daphnia and with other studies that show an association between energy cost and immune response in this system (Little and Killick 2007; Labbe et al. 2010; Allen and Little 2011). However, we cannot explain the generally high mortality rate in our control treatment.

There are three potential reasons for why the $D$. magna clones in our study did not get infected by $P$. ramosa. First of all, it is possible that either during parasite isolation from the sediment or during enrichment of parasite spores, M10 clones were infected by parasite spores that were not infective for OM2 clones, even though $P$. ramosa from Knokke Nat have been shown to heavily infect D. magna clones from OM2 (Jansen et al. 2010). Second, it is possible that our additional round of infection of clone M10 resulted in a bottleneck with respect to the number of parasite lineages and that a strain was selected which by chance did not infect OM2 clones. Alternatively, it may be that, for unknown reasons, the number of viable $P$. ramosa spores decreased to below-threshold levels in the time between estimating their density and using them in the experiment. Low spore concentrations result in failure to induce disease (Ben-Ami et al. 2008). The observed increased mortality in our combined parasite $\times$ pesticide exposure treatment may thus be associated with either exposure to a below-threshold concentration of parasite spores or exposure to spores that were not infective.

We did not find support for our hypothesis that Daphnia hatched from sediment layer with higher spore densities can cope better with parasite infections. No effect of sediment layer on any measured trait was observed, which is in contrast to Decaestecker et al. (2007), who found a correlation between infectivity and year (represented by the different layers here) as well as with the study of Pauwels et al. (2010), who found differences in levels of Daphnia phenoloxidase activity over time. Unfortunately, while our parasite exposure treatment clearly elicited a significant effect in terms of mortality, the absence of visual signs of infection warns against overinterpretation of our lack of a differential response for Daphnia isolated from different sediment layers. If the exposure was successful in generating a stress response or boost in immune system functioning, but not strong enough to cause any infections, our results do not allow us to test for interaction effects between sediment layer (exposure to parasites in natural habitat) and infection dynamics. So while our results reveal an interesting effect of combined exposure on mortality, they may not provide a good test for our basic hypothesis.

Acknowledgments We thank Ellen Decaestecker for providing the hatchlings, several members of the Luc De Meester's group for their help during the experiment and Andreas Kretschmann for helping verifying the diazinon concentration. The manuscript improved by comments from Andreas Bruder, Christoph Tellenbach, Mat Seymour and two anonymous reviewers. This research was funded by the ETH Board (CCES-GEDIHAP), a Mobility Support from Eawag for $\mathrm{CB}$ and the KU Leuven Research Fund project PF/2010/07. MJ received a fellowship of the IWT, Flanders, while KP is a postdoctoral researcher with the FWO, Flanders.

\section{References}

Aggarwal M, Naraharisetti SB, Dandapat S, Degen GH, Malik JK (2008) Perturbations in immune responses induced by concurrent subchronic exposure to arsenic and endosulfan. Toxicology 251:51-60

Allen DE, Little TJ (2011) Identifying energy constraints to parasite resistance. J Evol Biol 24:224-229

Ben-Ami F, Regoes RR, Ebert D (2008) A quantitative test of the relationship between parasite dose and infection probability across different host-parasite combinations. Proc R Soc B Biol Sci 275:853-859

Braune P, Rolff J (2001) Parasitism and survival in a damselfly: does host sex matter? Proc R Soc B Biol Sci 268:1133-1137

Bryner SF, Rigling D (2011) Temperature-dependent genotypeby-genotype interaction between a pathogenic fungus and its hyperparasitic virus. Am Nat 177:65-74

Cáceres CE (1998) Interspecific variation in the abundance, production, and emergence of Daphnia diapausing eggs. Ecology 79:1699-1710

Carvalho GR, Wolf HG (1989) Resting eggs of lake-Daphnia. I. Distribution, abundance and hatching of eggs collected from various depths in lake sediments. Freshw Biol 22:459-470

Chambers HW (1992) Organophosphorus compounds: an overview. In: Chambers JE, Levi PE (eds) Organophosphates. Chemistry, fate, and effects. Academic Press, San Diego

Chu FLE, Hale RC (1994) Relationship between pollution and susceptibility to infectious-disease in the Eastern Oyster, Crassostrea-Virginica. Mar Environ Res 38:243-256

Coors A, De Meester L (2008) Synergistic, antagonistic and additive effects of multiple stressors: predation threat, parasitism and pesticide exposure in Daphnia magna. J Appl Ecol 45:1820-1828 
Coors A, De Meester L (2011) Fitness and virulence of a bacterial endoparasite in an environmentally stressed crustacean host. Parasitology 138:122-131

Coors A, Decaestecker E, Jansen M, De Meester L (2008) Pesticide exposure strongly enhances parasite virulence in an invertebrate host model. Oikos 117:1840-1846

Coors A, Vanoverbeke J, De Bie T, De Meester L (2009) Land use, genetic diversity and toxicant tolerance in natural populations of Daphnia magna. Aquat Toxicol 95:71-79

Cousyn C, De Meester L, Colbourne JK, Brendonck L, Verschuren D, Volckaert F (2001) Rapid local adaptation of zooplankton behavior to changes in predation pressure in absence of neutral genetic changes. Proc Natl Acad Sci USA 98:6256-6260

Daszak P, Cunningham AA, Hyatt AD (2000) Wildlife ecology-Emerging infectious diseases of wildlife — threats to biodiversity and human health. Science 287:443-449

De Meester L, Mergeay J, Michels H, Decaestecker E (2007) Reconstructing microevolutionary dynamics from layered egg banks. In: Alekseev V, De Stasio B, Gilbert J (eds) Diapause in aquatic invertebrates theory and human use. Springer, pp 159-166

Decaestecker E, Lefever C, De Meester L, Ebert D (2004) Haunted by the past: evidence for dormant stage banks of microparasites and epibionts of Daphnia. Limnol Oceanogr 49:1355-1364

Decaestecker E, Gaba S, Raeymaekers JAM, Stoks R, Van Kerckhoven L, Ebert D, De Meester L (2007) Host-parasite 'Red Queen' dynamics archived in pond sediment. Nature 450:870-873

Ebert D (2005) Ecology, epidemiology, and evolution of parasitism in Daphnia. National Library of Medicine (US), National Center for Biotechnology Information, Bethesda

Ebert D, Rainey P, Embley TM, Scholz D (1996) Development, life cycle, ultrastructure and phylogenetic position of Pasteuria ramosa metchnikoff 1888: rediscovery of an obligate endoparasite of Daphnia magna Straus. Philos Trans R Soc 351:1689-1701

Galloway T, Handy R (2003) Immunotoxicity of organophosphorous pesticides. Ecotoxicology 12:345-363

Gendron AD, Marcogliese DJ, Barbeau S, Christin MS, Brousseau P, Ruby S, Cyr D, Fournier M (2003) Exposure of leopard frogs to a pesticide mixture affects life history characteristics of the lungworm Rhabdias ranae. Oecologia 135:469-476

Hairston NG Jr, Lampert W, Caceres CE, Holtmeier CL, Weider LJ, Gaedke U, Fischer JM, Fox JA, Post DM (1999) Lake ecosystems: rapid evolution revealed by dormant eggs. Nature 401:446

Hairston NG, Holtmeier CL, Lampert W, Weider LJ, Post DM, Fischer JM, Caceres CE, Fox JA, Gaedke U (2001) Natural selection for grazer resistance to toxic cyanobacteria: evolution of phenotypic plasticity? Evolution 55:2203-2214

Holmstrup M, Bindesbol AM, Oostingh GJ, Duschl A, Scheil V, Kohler HR, Loureiro S, Soares A, Ferreira ALG, Kienle C, Gerhardt A, Laskowski R, Kramarz PE, Bayley M, Svendsen C, Spurgeon DJ (2010) Interactions between effects of environmental chemicals and natural stressors: a review. Sci Total Environ 408:3746-3762

Jansen M, Stoks R, Decaestecker E, Coors A, Van de Meutter F, De Meester L (2010) Local exposure shapes spatial patterns in infectivity and community structure of Daphnia parasites. J Anim Ecol 79:1023-1033

Jansen M, Stoks R, Coors A, van Doorslaer W, de Meester L (2011) Collateral damage: rapid exposure-induced evolution of pesticide resistance leads to increased susceptibility to parasites. Evolution 65:2681-2691

Jeppesen E, Leavitt P, De Meester L, Jensen JP (2001) Functional ecology and palaeolimnology: using cladoceran remains to reconstruct anthropogenic impact. Trends Ecol Evol 16:191-198

Jokela J, Taskinen J, Mutikainen P, Kopp K (2005) Virulence of parasites in hosts under environmental stress: experiments with anoxia and starvation. Oikos 108:156-164

Kawecki TJ, Ebert D (2004) Conceptual issues in local adaptation. Ecol Lett 7:1225-1241

Kerfoot WC, Weider LJ (2004) Experimental paleoecology (resurrection ecology): chasing Van Valen's Red Queen hypothesis. Limnol Oceanogr 49:1300-1316

Kerfoot WC, Robbins JA, Weider LJ (1999) A new approach to historical reconstruction: combining descriptive and experimental paleolimnology. Limnol Oceanogr 44:12321247

King KC, McLaughlin JD, Boily M, Marcogliese DJ (2010) Effects of agricultural landscape and pesticides on parasitism in native bullfrogs. Biol Conserv 143:302-310

Klüttgen B, Dulmer U, Engels M, Ratte HT (1994) Adam, an artificial freshwater for the culture of zooplankton. Water Res 28:743-746

Konstantinou IK, Hela DG, Albanis TA (2006) The status of pesticide pollution in surface waters (rivers and lakes) of Greece. Part I. Review on occurrence and levels. Environ Pollut 141:555-570

Kretschmann A, Ashauer R, Preuss TG, Spaak P, Escher BI, Hollender J (2011) Toxicokinetic model describing bioconcentration and biotransformation of diazinon in Daphnia magna. Environ Sci Technol 45:4995-5002

Kreutz LC, Barcellos LJG, Marteninghe A, dos Santos ED, Zanatta R (2010) Exposure to sublethal concentration of glyphosate or atrazine-based herbicides alters the phagocytic function and increases the susceptibility of silver catfish fingerlings (Rhamdia quelen) to Aeromonas hydrophila challenge. Fish Shellfish Immunol 29:694-697

Krist AC, Jokela J, Wiehn J, Lively CM (2004) Effects of host condition on susceptibility to infection, parasite developmental rate, and parasite transmission in a snail-trematode interaction. J Evol Biol 17:33-40

Labbe P, Vale P, Little T (2010) Successfully resisting a pathogen is rarely costly in Daphnia magna. BMC Evol Biol 10:355

Lindström KM, Foufopoulos J, Pärn H, Wikelski M (2004) Immunological investments reflect parasite abundance in island populations of Darwin's finches. Proc R Soc B Biol Sci 271:1513-1519

Little T, Killick SC (2007) Evidence for a cost of immunity when the crustacean Daphnia magna is exposed to the bacterial pathogen Pasteuria ramosa. Ecology 76:1202-1207

Marcogliese DJ, Pietrock M (2011) Combined effects of parasites and contaminants on animal health: parasites do matter. Trends Parasitol 27:123-130

Maxwell DM, Brecht KM, Koplovitz I, Sweeney RE (2006) Acetylcholinesterase inhibition: does it explain the toxicity 
of organophosphorus compounds? Arch Toxicol 80: 756-760

McDowell JE, Lancaster BA, Leavitt DF, Rantamaki P, Ripley B (1999) The effects of lipophilic organic contaminants on reproductive physiology and disease processes in marine bivalve molluscs. Limnol Oceanogr 44:903-909

Metchnikoff E (1888) Pasteuria ramosa un representant des bacteries à division longitudinale. Ann I Pasteur Paris 4:165-170

Norris K, Evans MR (2000) Ecological immunology: life history trade-offs and immune defense in birds. Behav Ecol 11:19-26

Oostingh GJ, Wichmann G, Schmittner M, Lehmann I, Duschl A (2009) The cytotoxic effects of the organophosphates chlorpyrifos and diazinon differ from their immunomodulating effects. J Immunotoxicol 6:136-145

Pauwels K, De Meester L, Put S, Decaestecker E, Stoks R (2010) Rapid evolution of phenoloxidase expression, a component of innate immune function, in a natural population of Daphnia magna. Limnol Oceanogr 55:1408-1413

Relyea RA (2003) Predator cues and pesticides: a double dose of danger for amphibians. Ecol Appl 13:1515-1521

Rohr JR, Raffel TR, Sessions SK, Hudson PJ (2008) Understanding the net effects of pesticides on amphibian trematode infections. Ecol Appl 18:1743-1753

Sanchez M, Ferrando MD, Sancho E, Andreu-Molinar E (1998) Evaluation of a Daphnia magna renewal life-cycle test method with diazinon. J Environ Sci Health Part B Pestic Food Contam Agric Wastes 33:785-797
Schmid-Hempel P, Ebert D (2003) On the evolutionary ecology of specific immune defence. Trends Ecol Evol 18:27-32

Schoebel CN, Wolinska J, Spaak P (2010) Higher parasite resistance in Daphnia populations with recent epidemics. J Evol Biol 23:2370-2376

Sheldon BC, Verhulst S (1996) Ecological immunology: costly parasite defences and trade-offs in evolutionary ecology. Trends Ecol Evol 11:317-321

Sih A, Bell AM, Kerby JL (2004) Two stressors are far deadlier than one. Trends Ecol Evol 19:274-276

Singer H, Jaus S, Hanke I, Luck A, Hollender J, Alder AC (2010) Determination of biocides and pesticides by on-line solid phase extraction coupled with mass spectrometry and their behaviour in wastewater and surface water. Environ Pollut 158:3054-3064

Van Doorslaer W, Stoks R, Duvivier C, Bednarska A, De Meester L, Travisano M (2009) Population dynamics determine genetic adaptation to temperature in Daphnia. Evolution 63:1867-1878

Wittmer IK, Bader HP, Scheidegger R, Singer H, Luck A, Hanke I, Carlsson C, Stamm C (2010) Significance of urban and agricultural land use for biocide and pesticide dynamics in surface waters. Water Res 44:2850-2862

Yin M, Laforsch C, Lohr JN, Wolinska J (2011) Predatorinduced defence makes Daphnia more vulnerable to parasites. Evolution 65:1482-1488 